\title{
VIOLÊNCIA ESCOLAR E AUTO-ESTIMA DE ADOLESCENTES
}

\section{LUCIMAR CÂMARA MARRIEL}

Centro Latino-Americano de Estudos de Violência e Saúde Jorge Careli - Claves Escola Nacional de Saúde Pública/Instituto Fernandes Figueira/Fiocruz lucimar@claves.fiocruz.br

\section{SIMONE G. ASSIS}

simone@claves.fiocruz.br

\section{JOVIANA Q. AVANCI}

joviana@claves.fiocruz.br

\author{
RAQUEL V. C. OLIVEIRA \\ roliveira@claves.fiocruz.br
}

Pesquisadoras do Claves

\section{RESUMO}

\begin{abstract}
Este artigo procura estudar a associação entre auto-estima e violências que ocorrem no ambiente escolar. Apresenta resultados obtidos em pesquisa realizada em escolas públicas e particulares de São Gonçalo, Estado do Rio de Janeiro. Emprega basicamente metodologia quantitativa (inquérito epidemiológico com uma amostra de 1.686 alunos) com alunos das $7^{a}$ e $8^{a}$ séries do ensino fundamental e $1^{\circ}$ e $2^{\circ}$ anos do ensino médio. Os resultados indicam que alunos com baixa auto-estima relacionam-se de forma pior com colegas e professores que os pares de elevada auto-estima, além de se colocarem mais freqüentemente na posição de vitimas de violência na escola e terem mais dificuldade de se sentir bem no espaço escolar. São apontados alguns programas nacionais que têm tentado abordar o problema da violência na escola.
\end{abstract}

AUTO-ESTIMA - VIOLENNCIA - ESCOLAS - RELAÇÕES PROFESSOR-ALUNO

\section{ABSTRACT}

VIOLENCE AT SCHOOL AND TEENAGER'S SELF-ESTEEM. The purpose of this article is to study the relationship between self-esteem and the acts of physical and psychological

A pesquisa contou com o apoio do Conselho Nacional de Desenvolvimento Científico e Tecnológico - CNPq - e da Fundação de Amparo à Pesquisa do Estado do Rio de Janeiro - Faperj. 
violence that arise in school. It provides results a research carried out both in public and private schools in São Gonçalo, Rio de Janeiro State. An epidemiological survey with a sample of I,686 students was used with $7^{\text {th }}$ and $8^{\text {th }}$ grade elementary and 1 st and $2^{\text {nd }}$ grade secondary school students. As pointed out by the results, for those students with a low self-esteem it seems to be more difficult to get along both with classmates and teachers than for those with a high self-esteem. Not to mention that more often than the others the former pose as victims of violence at school and find it more difficult to feel at home there. This paper addresses some Brazilian programs which have been attempting to approach the issue of violence at school.

SELF-ESTEEM - VIOLENCE - SCHOOLS - STUDENT TEACHER RELATIONSHIP

A escola é um lugar privilegiado para refletir sobre as questões que envolvem crianças e jovens, pais e filhos, educadores e educandos, bem como as relações que se dão na sociedade. É também nesse universo onde a socialização, a promoção da cidadania, a formação de atitudes, opiniões e o desenvolvimento pessoal podem ser incrementados ou prejudicados.

Neste sentido, cabe à instituição escolar refletir e discutir temas que afligem a humanidade em seu cotidiano, dentre os quais se destacam a violência, suas formas de prevenção e as possíveis repercussões no desenvolvimento da criança e do adolescente. Essa responsabilidade social se deve, em parte, ao reconhecimento de que a esfera de convivência repercute diretamente na socialização infanto-juvenil, além de ser, juntamente com a família, espaço crucial para defesa dos direitos humanos (Njaine, Minayo, 2003).

É reconhecido e noticiado pela mídia que a escola, de modo concomitante e paradoxal, além de se instituir como instância de aprendizagem de conhecimento e de valores, bem como de exercício da ética e da razão, tem-se configurado como um espaço de proliferação de violências, incluindo, brigas, invasões, depredações e até mortes. É um espaço em que os alunos, em plena fase de desenvolvimento, se deparam com, constroem e elaboram experiências de violência. Freqüentemente, a vulnerabilidade social refletida na vivência escolar reduz a força socializadora da escola, interferindo no ambiente relacional e permitindo que os alunos construam a violência como uma forma habitual de experiência escolar (Camacho, 2000). Todavia os alunos são ao mesmo tempo socializados e singulares; lapidados pela escola e pela sociedade, ao mesmo tempo constroem a si próprios.

Estudando a temática, Camacho (2000) aponta duas formas básicas de violência na escola: física (brigas, agressões físicas e depredações) e não física 
(ofensas verbais, discriminações, segregações, humilhações e desvalorização com palavras e atitudes de desmerecimento), sendo a última, muitas vezes, disfarçada, mascarada e de difícil diagnóstico. Essas experiências aniquiladoras ocorrem nos diversos níveis de relações, podendo ter como agente tanto alunos como professores e funcionários, em seus diversos arranjos, quer como protagonistas quer como vítimas.

A existência de bullying nas escolas tem sido tema reiteradamente investigado nos últimos anos, no exterior e no Brasil. $\bigcirc$ termo em inglês refere-se a uma denominação diferenciada para a violência nesse âmbito, evidenciando uma repercussão negativa da violência nas relações entre pares, com destaque para o ambiente escolar. Bullying caracteriza-se por atos repetitivos de opressão, tirania, agressão e dominação de pessoas ou grupos sobre outras pessoas ou grupos, subjugados pela força dos primeiros. Trata-se de indivíduos valentes e brigões que põem apelidos pejorativos nos colegas, aterrorizam e fazem sofrer seus pares, ignoram e rejeitam garotos da escola, ameaçam, agridem, furtam, ofendem, humilham, discriminam, intimidam ou quebram pertences dos colegas, entre outras ações destrutivas (Lopes, Aramis, Saavedra, 2003).

Comportamentos agressivos, antes não tidos como violentos, têm sido nomeados como tal, sendo debatidas possibilidades de intervenção no ambiente escolar. Adolescentes vítimas do bullying geralmente são pessoas com dificuldades para reagir diante das situações agressivas, retraindo-se, o que pode contribuir para a evasão escolar, já que, muitas vezes, não conseguem suportar a pressão a que são submetidos.

Formas de violência mais sutis e de menor visibilidade, mas nem por isso menos importantes, também fazem parte do cotidiano das instituições de ensino. Pode-se considerar ainda a instituição de ensino e os educadores como possíveis agentes de violência, mediante ações como a imposição de conteúdos destituídos de interesse e de significado para a vida dos alunos, o precário conteúdo ministrado, a pressão a partir do poder de conferir notas, a ignorância quanto aos problemas dos alunos, o tratamento pejorativo, incluindo as agressões verbais e a exposição do aluno ao ridículo, no caso de incompreensão a algum conteúdo de ensino (Guimarães, 1992).

Reconhece-se que, em parte, essas formas de violência são acontecimentos corriqueiros e arraigados na prática educacional. Requerem transformações profundas e macrossociais, já que fazem parte da historicidade do agir educa- 
tivo, o que contribui para a sua banalização ou legitimação como mecanismo para resolver conflitos.

De maneira geral, a violência manifesta uma afirmação de poder sobre o outro e a conquista desse poder é o que gera as diversas formas de violência. Suas ocorrências são conseqüência das práticas cotidianas de discriminação, preconceito, da crise de autoridade do mundo adulto ou da fraca capacidade demonstrada pelos profissionais de criar mecanismos justos e democráticos de gestão da vida escolar. De modo geral, as escolas lidam com esses conflitos valendo-se de um elenco de procedimentos formais e informais, modelados diferentemente, de acordo com as características de cada direção ou projeto pedagógico.

Outra forma de violência é a restrição do aluno ao convívio em sala de aula, onde, muitas vezes, reinam a apatia, o tédio, o ressentimento, a alienação, a atitude destrutiva e as agressões físicas, principalmente por parte daqueles alunos que sofrem frustração substancial fora da escola (Lembo, 1975). Neste sentido, as violências que ocorrem na escola devem ser compreendidas à luz da violência vivida e testemunhada extramuro escolar.

Nunes e Abramovay (2003) enumeram alguns aspectos explicativos ou associativos da violência escolar: I. gênero - meninos se envolvem mais em situações de violência, seja como vítimas ou autores; 2 . idade - o comportamento agressivo é associado ao ciclo etário; 3. etnia - resistência dos alunos de minorias étnicas ao tratamento discriminatório por parte de colegas e professores; 4. família - alvo de controvérsia, especialmente pelas "características sociais das famílias violentas"; 5. ambiente externo - comunidades com sinais de abandono ou decadência estão mais vulneráveis à violência; 6. insatisfação/ frustração com as instituições e a gestão pública - falta de equipamentos e recursos didáticos e humanos, além da baixa qualidade do ensino; 7. exclusão social - restrições à incorporação de parte da população à comunidade política e social; 8. exercício de poder - desestímulo e discriminações contribuindo para desrespeitar os direitos humanos dos alunos à proteção.

Embora presente no debate público, Sposito (2002) assinala que a pesquisa sobre violência e escola ainda é incipiente no Brasil. Apresentando dados do único levantamento nacional que abordou a violência escolar, publicado em 1998, apresenta três tipos de situações mais freqüentes: depredações, furtos ou roubos que atingem o patrimônio; agressões físicas entre os alunos; agressões de alunos contra professores. 
Não obstante, estão praticamente ausentes os estudos que investigam questões individuais que podem estar associadas à violência escolar. As relações estabelecidas na escola, incluindo a vivência de violência, têm papel relevante, porém pouco conhecido na visão de si do aluno.

Com tal propósito, este trabalho objetiva mostrar algumas formas de violência habitual, vivida pelos alunos intramuros da escola e a relação que possui com a auto-estima dos adolescentes. Parte-se da premissa de que a experiência de violência na escola está associada ao nível de auto-estima do aluno.

Compreende-se a auto-estima como um juízo pessoal de valor, externado nas atitudes que o indivíduo tem consigo mesmo. É uma experiência subjetiva, à qual as pessoas têm acesso mediante relatos verbais e comportamentos observáveis (Coopersmith, 1967). A percepção que o indivíduo tem do seu próprio valor e a avaliação que faz de si mesmo em termos de competência constituem pilares fundamentais da auto-estima. Estudiosos sugerem que esse julgamento pessoal é formado desde a infância (Rosenberg, 1989, Mruk, 1995).

A premissa que norteia o trabalho é baseada no conhecimento de que pessoas significativas para a criança e o adolescente tomam lugar de destaque na formação da auto-estima, em especial pais, professores e amigos (Assis, Avanci, 2004). Assim, se essas relações forem constituídas por atitudes violentas, parece haver maior probabilidade de serem associadas a um sentimento negativo de si: a baixa auto-estima.

\section{METODOLOGIA}

A população de referência para o estudo foi composta por 1.686 estudantes de II a 19 anos de $7^{\mathrm{a}}$ e $8^{\mathrm{a}}$ séries do ensino fundamental e I $^{\mathrm{a}}$ e $2^{\mathrm{a}}$ séries do ensino médio, em 19 escolas públicas (municipais e estaduais) e 19 particulares de São Gonçalo, Estado do Rio de Janeiro, no ano de 2002. Os estudantes foram escolhidos mediante amostragem aleatória, estratificada em um único estágio de seleção, tendo as turmas sido assumidas como unidades conglomeradas.

Utilizou-se um instrumento de avaliação fechado, anônimo e autopreenchível, testado em estudo piloto com 210 adolescentes, com dupla aplicação no intervalo de sete a dez dias, com a finalidade de estudar a sua confiabilidade e validade. Dentre outros "medidores", foram empregados: 
- Escala de Rosenberg (1989) de 1965, para avaliar a auto-estima dos alunos. Essa escala é uma medida unidimensional tipo Guttman (opções de resposta: concordo totalmente, concordo, discordo, discordo totalmente), com dez itens usados como indicadores para avaliar a atitude positiva ou negativa de si mesmo. Altos escores indicam alta autoestima. Tem demonstrado boas propriedades psicométricas e fácil aplicabilidade em estudos internacionais. Realizou-se a adaptação transcultural dessa escala e obteve-se a de Cronbach de 0.68, Correlação Intraclasse (ICC) de 0.70 e kappa predominantemente moderado.

- Inventário de auto-estima (Coopersmith, 1967), para aferir a autoestima na escola. Contém 58 itens, divididos em quatro dimensões: eu geral, grupo social, família e escola, que podem ser pontuados separadamente segundo duas possibilidades de respostas, "tem a ver comigo" ou "não tem a ver comigo". Originalmente, em sua forma final, essa escala foi ministrada em 87 alunos americanos das $5^{\text {as }}$ e $6^{\text {as }}$ séries, meninos e meninas. Neste estudo, o instrumento não foi utilizado na íntegra, apenas alguns itens da dimensão de escola foram aproveitados, o que equivale a cinco itens. Neste trabalho o instrumento não é utilizado como uma escala psicométrica, apresentandose apenas as questões isoladamente. $\bigcirc$ inventário apresentou boas qualidades psicométricas em estudos anteriores e é um dos mais citados na literatura, tendo sido utilizado no Brasil por Gobitta (2000).

- Escala de violência na escola, para avaliar essa experiência pelos alunos, utilizada pela ONU em pesquisas aplicadas em todo o mundo, inclusive no Brasil, sendo o Instituto Latino-Americano das Nações Unidas Para a Prevenção do Delito e Tratamento do Delinqüente llanud/ONU, responsável pela aplicação do instrumento no país. $\bigcirc$ estudo original no Brasil' foi desenvolvido pelo llanud (Kahn et al., 1999) em 40 escolas públicas e particulares nas $7^{a}$ e $8^{a}$ séries do ensino fundamental e $1^{\mathrm{a}}$ a $3^{\mathrm{a}}$ do ensino médio, no município de São Paulo, atingindo 1.026 crianças e adolescentes no âmbito escolar. $\bigcirc$

I. A pesquisa foi aprovada pelo Comitê de Ética em Pesquisa da Fundação Oswaldo Cruz, conforme a Resolução 196/96 do Conselho Nacional de Saúde 
indicador é constituído por oito questões dicotômicas, que visam avaliar se o respondente já sofreu as seguintes situações na escola: humilhação; ameaça; agressão forte de modo a precisar de curativos ou ir ao médico; danificação proposital de algum pertence; convívio com pessoas que carregam arma de fogo e/ou branca; furto de objeto; subtração à força de dinheiro ou alguma coisa. A variável violência na escola foi computada quando o respondente afirmava pelo menos um item da escala. Os resultados são apresentados item a item e não como escore global.

Os dados quantitativos foram submetidos a teste de qui-quadrado, que verifica as diferenças entre as proporções com determinação do nível de significância.

Complementarmente e de maneira ilustrativa, são apresentadas e discutidas falas de jovens com alta e baixa auto-estima, de acordo com os escores dos resultados quantitativos, provenientes de 13 entrevistas semi-estruturadas. Por meio dessas entrevistas procurou-se investigar a história de vida do aluno, vivências escolares, competência acadêmica e valores, atitudes e opiniões. Os alunos que participaram das entrevistas são chamados por nomes fictícios que começam com letras (B: para os jovens de baixa auto-estima (AE) e A: para os de alta auto-estima.

\section{RESULTADOS}

No quadro I pode-se verificar tendência geral de bom relacionamento dos alunos com seus amigos e professores, embora tenha se evidenciado uma relação mais positiva com os primeiros, em comparação ao relacionamento com professores. Observa-se, todavia, que os alunos de baixa auto-estima tendem a dizer menos que têm bom relacionamento e mais que a relação é regular ou ruim ( $p d \leqslant 0,000$ ). Depreende-se que $36,8 \%$ dos alunos de baixa auto-estima e $24,5 \%$ dos de elevada auto-estima se relacionam de forma regular ou ruim com seus educadores.

O relacionamento com educadores ocupou parte significativa da fala dos alunos. $\bigcirc$ autoritarismo dos professores aparece como um comportamento que faz com que os adolescentes se fechem para uma relação de confiança: 
...não, é que muitas vezes tem professor que quer falar mais alto, por exemplo, a gente está conversando e um aluno fala "Pôxa, professor, não é assim!" (...) "É assim sim!" Tenta colocar aquela autoridade ali, mas muitas das vezes está sendo errado, mal sabe ele que aquilo pode estar afetando nossa emoção ali mesmo, pode ser uma coisa que não deve, aí fica nisso. (Antônio)

QUADRO I

RELACIONAMENTO COM PROFESSORES E AMIGOS

\begin{tabular}{|l|l|l|c|c|c|}
\hline \multirow{2}{*}{ Relacionamento na escola } & \multirow{2}{*}{ Auto-estima } & \multicolumn{3}{|c|}{$\%$} & \multirow{2}{*}{ P valor } \\
\cline { 3 - 5 } & & Bom & Regular & Ruim & \\
\hline Relacionamento com & Alta $(n=934)$ & 93,7 & 6,2 & 0,1 & \multirow{2}{*}{0,000} \\
AMIGOS(AS) & Baixa $(n=640)$ & 87,8 & 11,4 & 0,8 & \\
\hline Relacionamento com & Alta $(n=925)$ & 75,6 & 23,5 & 1,0 & \multirow{2}{*}{0,000} \\
PROFESSORES & Baixa $(n=632)$ & 63,1 & 34,3 & 2,5 & \\
& & &
\end{tabular}

Os entrevistados também revelam incomodar-se com a maneira pela qual os professores chamam a sua atenção na sala de aula, com agressões verbais, o que provoca um distanciamento na relação e antipatia por parte dos adolescentes.

Então, ele [professor] falou que eu era indisciplinado, gritou, na frente de todo mundo. Então eu não gostava dele não (...) Ficava: "Ah seu burro! (...) Você não vai passar de ano nunca!" (Bento)

Não, apesar de que ninguém gosta de ser chamado a atenção, é meio chato, a sala cheia: "Fica quieto menino!" Ainda mais eu que converso aula toda, aí fica meio chato, fico assim, meio triste, abaixo a cabeça, mas discussão, discussão, nunca discuti com professor não. (Antônio)

A relação professor-aluno é, muitas vezes, permeada pela falta de limites e de respeito. Nas falas dos entrevistados, os professores abordam seus alunos da seguinte maneira:"está na minha lista", "vou te reprovar"; demonstrando o autoritarismo e o abuso de poder, o que cria uma barreira para a relação empática, tão necessária para a proteção e cuidado do aluno dentro do ambiente escolar, além de favorecer a baixa auto-estima. 
Concomitantemente, a desvalorização do professor pela sociedade leva o aluno também a desvalorizá-lo, daí o confronto fica de igual para igual. O respeito é uma palavra que flutua dentro do dicionário; para fixá-la é preciso que haja uma valorização de ambas as partes.

quadro 2 explicita algumas formas de violência vividas pelos alunos na escola, destacando-se aquelas mais relatadas pelos adolescentes de baixa autoestima: serem humilhados, ameaçados, agredidos intensamente e roubados na escola. Os resultados mostram também uma tendência a terem seus objetos pessoais destruídos por colegas $(p=0,054)$.

QUADRO 2

VITIMIZAÇÃO DOS ALUNOS NO ESPAÇO ESCOLAR SEGUNDO AUTO-ESTIMA

\begin{tabular}{|c|c|c|c|c|}
\hline \multirow{2}{*}{ Formas de violência na escola } & \multirow{2}{*}{ Auto-estima } & \multicolumn{2}{|c|}{$\%$} & \multirow{2}{*}{$P$ valor } \\
\hline & & Sim & Não & \\
\hline \multirow[t]{2}{*}{ Alguém humilhou você? } & Alta $(n=923)$ & 20,0 & 80,0 & 0,000 \\
\hline & Baixa $(n=620)$ & 34,2 & 65,8 & \\
\hline \multirow[t]{2}{*}{ Alguém ameaçou você? } & Alta $(n=9 \mid 4)$ & 15,6 & 84,4 & 0,004 \\
\hline & Baixa $(n=621)$ & 21,6 & 78,4 & \\
\hline Você foi agredido por alguém de forma & Alta $(n=9 \mid 7)$ & 2,3 & 97,7 & 0,001 \\
\hline $\begin{array}{l}\text { forte o bastante para que precisasse de } \\
\text { curativos ou ir ao médico? }\end{array}$ & Baixa $(n=620)$ & 5,6 & 94,4 & \\
\hline \multirow{2}{*}{$\begin{array}{l}\text { Alguém danificou de propósito alguma } \\
\text { coisa sua (como roupa, livros, relógio)? }\end{array}$} & Alta $(n=9 \mid 2)$ & 14,4 & 85,6 & 0,054 \\
\hline & Baixa $(n=6 \mid 7)$ & 18,2 & 81,8 & \\
\hline \multirow{2}{*}{$\begin{array}{l}\text { Você andou/conviveu com pessoas que } \\
\text { carregam arma de fogo (revólver, outros)? }\end{array}$} & Alta $(n=905)$ & 5,7 & 94,3 & 0,824 \\
\hline & Baixa $(n=6 \mid 0)$ & 6,1 & 93,9 & \\
\hline \multirow{2}{*}{$\begin{array}{l}\text { Você andou/conviveu com pessoas que } \\
\text { carregam arma branca (faca, canivete, } \\
\text { punhal)? }\end{array}$} & Alta $(n=9 \mid 0)$ & 5,8 & 94,2 & 0,587 \\
\hline & Baixa $(n=6 \mid 4)$ & 6,5 & 93,5 & \\
\hline \multirow[t]{2}{*}{ Alguém furtou de você algum objeto? } & Alta $(n=920)$ & 28,0 & 72,0 & 0,456 \\
\hline & Baixa $(n=623)$ & 29,9 & 70,1 & \\
\hline \multirow{2}{*}{$\begin{array}{l}\text { Alguém tirou à força dinheiro ou alguma } \\
\text { coisa de você? }\end{array}$} & Alta $(n=9 \mid 6)$ & 2,1 & 97,9 & 0,040 \\
\hline & Baixa $(n=6 \mid 8)$ & 3,9 & 96,1 & \\
\hline
\end{tabular}

No quadro 2, como se pode verificar, 34,2\% dos adolescentes com sentimento depreciativo por si referem ser humilhados na escola, em relação a 
20\% dos de auto-estima mais elevada. Parte desta humilhação decorre de brincadeiras entre amigos, opiniões negativas dos educadores e discriminações. Principalmente entre alunos das escolas públicas percebeu-se muitos constrangimentos em relação a pessoas externas à escola: "a gente se sente assim, meio constrangido, não é, pô muitas pessoas de colégios passam ali pela frente..." (Antônio).

Continuando no quadro 2, podemos observar que as armas de fogo e as armas brancas estão próximas das escolas. A pesquisa revela valores similares, independente do nível de auto-estima dos estudantes. Aproximadamente $6 \%$ já conviveram com pessoas que portavam esses instrumentos. Ainda neste quadro, o furto aparece com um percentual bastante alto na vida dos jovens, o que pode propagar o sentimento de medo e insegurança.

O termo mais empregado pelos adolescentes para identificar a relação entre colegas foi a "zoação", gíria que leva a diversos sinônimos, também simbólicos, tais como encarnação, humilhação, violação e outras maneiras de violência "invisível".

Ele [colega] ficava implicando comigo (...) Ficava me zoando, aí dava soquinho nas costas. Aí eu dava porradão mesmo (...) Ele pegou uma folha da bananeira; começou a tentar me bater assim, eu saí para cima, saí... aí eu pulei em cima dele, reboquei ele e dei um soco. Aí fica todo mundo idolatrando... (Alberto)

A necessidade do domínio do "território" provoca a violência. Sobrevive quem é mais forte. "Que a gente se dava soquinho (...) Ele gostava muito de brigar. Só que eu era mais forte... aí eu dei um soco na cara dele. Ele era gurizinho. Era menor... aí quebrei o nariz dele" (Bruno). No entanto, quem não reage, sofre, pois fica exposto ao olhar dos amigos como fraco, sem moral, ridicularizado por sua falta de defesa. "E ele [colega] fica sendo zoado, porque apanhou" (Alessandro).

As diversas formas de violência sutis aparecem em algumas falas dos adolescentes entrevistados, não se diferenciando com clareza situações relatadas por alunos de baixa e alta auto-estima. Isso indica a proximidade de todos os jovens à violência na escola.

quadro 3 revela que 35,2\% dos adolescentes de baixa auto-estima comentam que se sentem desencorajados na escola (17,6\% entre os de elevada 
auto-estima). $\bigcirc$ aluno frustrado desencadeia uma série de comportamentos negativos para si. Na fala dos alunos com baixa auto-estima aparecem mais freqüentemente brincadeiras pejorativas e sofrimento emocional: "quando me chamaram de fofoqueiro, me senti rejeitado porque, podia sair de perto" (Ângelo). Alunos que sofrem de um sentimento negativo por si sentem-se mais desencorajados e aborrecidos na escola, além de expressarem mais o desejo de ir melhor na escola, quando se os compara com seus pares de maior auto-estima.

Embora muitos alunos sintam orgulho do que fazem nas suas escolas, os de elevada auto-estima se mostram mais otimistas a este respeito. $\bigcirc$ esporte aparece como uma atividade que traz muito prazer à vida dos adolescentes, que demonstram grande dedicação e orgulho de representarem o seu time e a sua escola. Gostam quando tiram notas boas e quando são elogiados pelos professores.

QUADRO 3

VISÃO DE SI NA ESCOLA SEGUNDO NÍVEIS DE AUTO-ESTIMA DOS ALUNOS

\begin{tabular}{|l|c|c|c|c|}
\hline \multirow{2}{*}{ Visão de si na escola } & \multirow{2}{*}{ Auto-estima } & \multicolumn{2}{c|}{$\%$} & \multirow{2}{*}{ P valor } \\
\cline { 3 - 4 } & & Sim & Não & \\
\hline Sinto-me com freqüência desencorajado(a) & Alta $(n=937)$ & 17,6 & 82,4 & \multirow{2}{*}{0,000} \\
na escola & Baixa $(n=640)$ & 35,2 & 64,8 & \\
\hline Geralmente me sinto aborrecido(a) na & Alta $(n=938)$ & 27,7 & 72,3 & 0,000 \\
escola & Baixa $(n=641)$ & 44,9 & 55,1 & \\
\hline Sinto orgulho do que faço na escola & Alta $(n=926)$ & 88,1 & 11,9 & \multirow{2}{*}{0,000} \\
& Baixa $(n=636)$ & 73,9 & 26,1 & \\
\hline Eu gostaria de ir melhor na escola & Alta $(n=925)$ & 65,7 & 34,3 & \multirow{2}{*}{0,000} \\
& Baixa $(n=637)$ & 79,3 & 20,7 & \\
\hline Meus professores fazem com que sinta que & Alta $(n=939)$ & 16,4 & 83,6 & 0,094 \\
não sou bom aluno & Baixa $(n=642)$ & 19,8 & 80,2 & \\
\hline
\end{tabular}

\section{DISCUSSÃO}

Ao longo do trabalho ficou evidente que alunos de baixa auto-estima têm relacionamentos mais difíceis na escola, colocando-se mais freqüentemente na posição de vítimas de violência. Têm ainda mais dificuldade de se sentir bem 
nesse espaço, configurando um perfil de aluno que merece ser priorizado nas práticas educativas.

Este trabalho não responde a nenhuma prerrogativa de causalidade, todavia é fundamental entender que o aluno com baixa auto-estima parece ser mais vulnerável às diversas formas de violência, vividas intra ou extramuros da escola (Assis et al., 2004). E, independente do nível de auto-estima, sabe-se que experiências de violência acarretam prejuízo à existência humana.

Estatuto da Criança e do Adolescente assegura a proteção às crianças, mas o controle e a percepção da violência ao redor delas cabe a cada órgão que tem contato mais direto com essas crianças, no caso a escola e a família. Sobre a escola recai grande obrigação de socialização de crianças e adolescentes, provenientes de diversos ambientes e com distintos hábitos e atitudes.

Nesse cenário é mister pensar em estratégias preventivas e de combate à violência escolar. Quase sempre a perspectiva de um trabalho de prevenção na escola acontece motivado por situações emergenciais, o que favorece a distorção dos legítimos objetivos da prevenção como prática social institucionalizada (Lara, 200 I). Diante das situações de violência, a escola geralmente adota medidas repressivas, o que não soluciona o problema substancialmente e a longo prazo.

Seria impossível discutir neste artigo as múltiplas formas de enfrentamento da violência em seus variados níveis: institucional - provocada pelas condições socioeconômicas e culturais mais gerais e pela atuação das diversas instituições sociais, como a escola; interpessoal - manifestada nas relações entre pessoas e grupos; e individual - momento único em que cada indivíduo faz a síntese e representa todas as suas vivências e violências sofridas.

Por esta razão, optou-se por destacar algumas questões. Uma delas, muito promissora e estratégica, é a necessidade de reconhecer a escola como lugar privilegiado de transformação para uma sociedade menos violenta, pelo seu potencial que vai além da transmissão de conhecimentos. Investir na inserção de valores e conhecimentos paralelamente à das disciplinas exigidas para a formação acadêmica dos alunos é um caminho bastante frutífero.

Investir na melhoria da relação professor-aluno é um alvo a ser destacado, dada a sua relevância na atuação sob a violência e no desenvolvimento de características individuais, como a auto-estima.

A premissa do professor forte e aluno fraco precisa ser desenraizada das práticas educativas. A escola regida pelo modelo tradicional, com o manejo da 
classe nas mãos do professor e os alunos em posição de obediência e subalternidade, perdeu-se no tempo. A hierarquia fica menos visível na sala de aula onde vigoram a discussão e os novos modelos de relações entre professores e alunos. Esses modelos com maior elasticidade e tolerância, produzem relacionamentos menos violentos e mais prazerosos. Contudo, implicam novas definições de disciplina.

É preciso reconhecer que o termo indisciplina não se restringe apenas a desordem, descontrole e falta de regras, mas também, ao processo de construção de conhecimento; provoca falas, movimento, rebeldia, oposição, inquietação e busca de respostas, o que pode causar desconforto para o corpo docente. Sob o aspecto positivo, a indisciplina se torna resistência à dominação, submissão às injustiças, desigualdades e discriminações em busca da identidade e dos direitos (Camacho, 2000).

Por outro lado, há que se debater as dificuldades enfrentadas pelos professores, haja vista os problemas que circundam seu ofício. A baixa valorização dos professores e a falta de tempo para reciclagens são algumas das muitas dificuldades enfrentadas por essa categoria. Muitos profissionais de educação revelam trabalhar em inúmeras escolas, o que pode acarretar níveis elevados de estresse, ao ponto de eles não conseguirem ater-se ao seu dia-a-dia e ao seu trabalho, nem sempre reconhecido e tão pouco valorizado.

A realidade enfrentada do professor brasileiro foi evidenciada em pesquisa feita pela Unesco, com apoio do Instituto Nacional de Estudos e Pesquisas Educacionais Anísio Teixeira (Inep, 2004). O perfil dos professores brasileiros revela que $60 \%$ dos educadores de ensino fundamental têm mais de 100 alunos, considerando todas as escolas em que trabalham e 18,7\% dos professores atendem mais de 400 alunos. No ensino médio 51 , 8\% dos profissionais da educação, têm de 10 I a 400 estudantes e $42,2 \%$ possuem mais de 400 alunos. Este trabalho relata ainda que mais de $40 \%$ dos professores trabalham em mais de uma escola e que quase 15\% desses profissionais da educação exercem mais de 40 horas semanais. Há que se pensar na capacidade de oferecer atenção individualizada, diante desse excesso de contingente atendido por cada educador.

A formação continuada dos educadores é outro tema que precisa ser destacado na sociedade. Professores despreparados podem acentuar comportamentos mais arredios, especialmente quando deixam sem resposta indagações importantes dos alunos, levando a uma revolta involuntária. Idealmente, o pro- 
fessor poderia funcionar como agregador social, acompanhando a vida do educando e relacionando-se com a família e a comunidade (Reichel, s.d.).

Acredita-se que os problemas desse grupo ocupacional mereçam ser considerados desafios para a sociedade, sem exonerar a responsabilidade individual no processo e buscando uma prática eficiente do professor, em que o afeto, a competência na detecção e enfrentamento da violência possam ser ingredientes fundamentais e transformadores.

No contexto atual é difícil, mas não impossível, uma atividade docente eficaz. Atitudes aparentemente simples, afetuosas e que expressam respeito, muitas vezes, consideradas banais e sem maiores conseqüências, podem ter efeito positivo, aliviando inclusive conflitos comuns a essa fase da vida dos adolescentes. Confiar e acreditar na capacidade dos alunos, criar situações educativas de forma que eles possam se expressar, propiciando vivência prazerosa e entrosamento com os estudantes, é uma forma eficiente de promover a autoestima e colaborar com a diminuição da violência dentro do ambiente escolar. Essa constatação baseia-se no conhecimento de que a auto-estima que a criança aos poucos desenvolve é, em grande parte, interiorização da estima que se tem por ela e da confiança da qual é alvo.

A auto-estima poderá ser trabalhada para que o aluno tenha uma visão melhor de si. Esse enfoque poderá diminuir o conflito tanto na escola quanto na família, já que possibilita que o estudante lide mais facilmente com as mudanças que tem de enfrentar, em especial, na fase da adolescência. Além disso, favorece o respeito ao espaço dos colegas, da família, dos professores e dos outros indivíduos que fazem parte de sua vida.

No Brasil apenas recentemente iniciou-se reflexão mais sistematizada acerca do papel da escola diante da violência, e existem alguns projetos que procuram trabalhar com a questão. Um exemplo é o do trabalho feito pela Unesco com escolas inovadoras, realizado em 13 capitais brasileiras e no Distrito Federal, que analisa experiências desenvolvidas em escolas públicas situadas em locais de elevada vulnerabilidade social (Nunes, Abramovay, 2003). No estudo procura-se mostrar que algumas escolas que passaram por situações difíceis e que experimentaram diversas formas de violência e abandono conseguiram reverter o quadro por meio do estabelecimento de pactos de confiança e aposta nos jovens.

O programa de redução do comportamento agressivo entre estudantes, desenvolvido pela Associação Brasileira Multiprofissional de Proteção à Infân- 
cia e à Adolescência, no ano de 2000, sob o patrocínio da Petrobras, teve como intenção diagnosticar e atuar em situações de Bullying (Lopes, Aramis, Saavedra, 2003). Sua atuação atingiu 7.757 alunos da $5^{a}$ à $8^{a}$ série do ensino fundamental em onze escolas no Município do Rio de Janeiro, com o objetivo de reduzir o comportamento agressivo no ambiente escolar e intervir para a prevenção e redução do fenômeno.

Outra iniciativa inovadora é o Programa Cuidar (Modus Faciendi, 1999; Fiocruz, 2003). Baseando-se em uma modalidade de intervenção pedagógica realizada em cidades do Sudeste e Nordeste brasileiro, objetivou realizar um trabalho com jovens e adolescentes das escolas públicas e privadas. Envolveu toda a escola, agentes, educadores e educandos, pais e responsáveis em ações voltadas para a educação de valores, alinhada à ética da inclusão.

Enfrentar a violência requer iniciativas em vários níveis e de diferentes complexidades. Uma das ações que cabe à escola é o exercício do bom relacionamento e o cultivo da paz no ambiente. Tal qual afirma Guimarães, podemos lamentar e combater a violência escolar

...mas o importante é observar esse fenômeno em ação, analisar seus efeitos e compreender que os riscos de desordem sempre estarão presentes; eles são inevitáveis, incontroláveis e uma das saídas talvez seja [...] dar lugar à rupturas, por onde se alimentam as diferenças. Que o coletivo não seja uno e possibilite expressões rebeldes e inconformistas, que se crie uma dinâmica mais coletiva dentro da escola, abrindo espaço para o lúdico, para a imaginação. ( 1 992, p. 64)

E, concluimos, para o diálogo.

\section{REFERÊNCIAS BIBLIOGRÁFICAS}

ASSIS, S. G.; AVANCI, J. Q. Labirinto de espelhos: formação da auto-estima na infância e na adolescência. Rio de Janeiro: Fiocruz, 2004.

ASSIS, S. G. et al. Violência e representação social na adolescência no Brasil. Revista PanAmericana de Saúde Pública, v. 16, n. I, p.43-5। , 2004.

CAMACHO, L. M.Y. Violência e indisciplina nas práticas escolares de adolescentes: um estudo das realidades de duas escolas semelhantes e diferentes entre si. São Paulo, 2000. Tese (dout.) Universidade de São Paulo. 
COOPERSMITH, S. The Antecedents of self-esteem. San Francisco: Freeman, 1967.

FIOCRUZ. Escola Nacional de Saúde Pública. Avaliação do processo de implantação e dos resultados do "Programa Cuidar": 4ª fase. Rio de Janeiro: Claves, 2003. (Relatório de Pesquisa) GOBITTA, M. Estudo inicial do inventário de auto-estima: forma A. São Paulo, 2000. Dissert. (mestr.) Instituto de Psicologia e Fonoaudiologia, Pontifícia Universidade Católica de Campinas.

GUIMARÃES, A. M. A Escola e a ambigüidade. In: SILVA, A. et al. O Papel do diretor e a escola de 10 grau. São Paulo, 1992. p.5।-74.

INSTITUTO NACIONAL DE ESTUDOS E PESQUISA EDUCACIONAIS ANÍSIO TEIXEIRA. Informativo /NEP, v. 2, n.4l, 2004. Disponível em: < http://umwwinep.gov.br.> Acesso em: 29/9/2004.

KAHN, T. et al. O dia a dia nas escolas. São Paulo: Instituto Latino-Americano das Nações Unidas para a Prevenção do Delito e Tratamento do Delinqüente; Instituto Sou da Paz, 1999.

LARA, C. R. Violência escolar. por um olhar diferenciado do problema no contexto escolar. São Paulo, 200।. Tese (dout.) Universidade de São Paulo.

LEMBO, J. M. Porque falham os professores. São Paulo: EPU, 1975.

LOPES, N.; ARAMIS, A.; SAAVEDRA, L.H. Diga não para o Bullying: programa de redução do comportamento agressivo entre estudantes. Rio de Janeiro, 2003.

MODUS FACIENDI. Programa Cuidar: livro do professor. Belo Horizonte: 1999. v. I.

MRUK, C. Self-esteem: research, theory, and practice. New York: Springer, 1995.

NJAINE, K.; MINAYO, M. C. S. Violência na escola: identificando pistas para a prevenção. Revista Interface: Comunicação, Saúde, Educação, v.7, n. I3, p. I 1 9-134, 2003.

NUNES, M. F. R; ABRAMOVAY, M. Escolas inovadoras: experiências bem- sucedidas em escolas públicas. Brasília: Unesco; Fundação W. K. Kellogg; Unirio, 2003

REICHEL, S. Violência institucionalizada. In: RIO GRANDE DO SUL (GOVERNO). Assembléia Legislativa. Comissão de Cidadania e Direitos Humanos. Violência doméstica. Rio Grande do Sul, s.d. p.8-22.

ROSENBERG, M. Society and the adolescent self-image. Princeton, NJ: Princeton University Press, 1989.

SPOSITO, M. P. As Vicissitudes das políticas públicas de redução da violência escolar. In: WESTPHAL, M. F. Violência e criança. São Paulo: Edusp, 2002. p.249-266.

Recebido em: novembro 2004

Aprovado para publicação em: abril 2005 